\title{
Tetany and osteolysis in light chain myeloma with amyloidosis
}

\author{
H. L. BHAKRI \\ M.B., M.R.C.P. \\ T. F. CUNDY \\ M.D., M.R.C.P. \\ K. W. Pettingale \\ M.D., F.R.C.P. \\ Department of Medicine, King's College Hospital Medical School, London SE5 8RX
}

\begin{abstract}
Summary
A patient is described with light chain myeloma and amyloidosis in whom 2 unusual complications occurred, diffuse osteolytic lesions and tetany. These observations extend the previously recognized clinical spectrum of this disorder.
\end{abstract}

KEY WORDS: light chain myeloma, amyloid, osteolytic lesions, tetany, hypomagnesaemia.

\section{Introduction}

Widespread osteolytic lesions and hypercalcaemia are common in patients with all forms of malignant plasma cell dyscrasias, including light chain myeloma. However, in the sub-group of patients with light chain myeloma and amyloidosis the occurrence of radiographically evident lytic bone disease is rare. We wish to report an unusual case of systemic light chain myeloma in which tetany, related to small bowel amyloid, and diffuse skeletal disease coexisted.

\section{Case report}

A 58-year-old woman was admitted to hospital with a 2-week history of diarrhoea, weight loss and back pain. Skeletal radiographs revealed widespread lytic bone lesions, diffuse osteopenia, pathological rib fractures and spinal collapse (Fig. 1). The diagnosis of a malignant plasma cell dyscrasia was confirmed by the presence of kappa light chains in the urine and bone marrow examination. Only $4 \%$ of the marrow cells were plasma cells, but immunofluorescence studies showed that all those present were kappa chain producing. No monoclonal band was present in the serum. Barium studies and sigmoidoscopy revealed no cause for her diarrhoea and no pathogenic organisms could be isolated from the stool. Rectal biopsies were negative for amyloid. The diarrhoea

Correspondence to Dr Cundy improved after courses of antibiotics, prednisolone and parenteral feeding. However, she developed moderate hypocalcaemia $(2 \cdot 1 \mathrm{mmol} /$ litre $)$ with inappropriately high calcium excretion $(5.4 \mathrm{mmol} / \mathrm{day})$. Treatment was begun with oral calcium $(4 \mathrm{mmol}$ / day) and vitamin $D_{2}(25 \mu \mathrm{g} /$ day $)$. When the diarrhoea had resolved, she was treated with a 4-day course of melphalan ( $5 \mathrm{mg} /$ day) and prednisolone (40 mg/day).

Three weeks later, she was re-admitted with congestive cardiac failure, paraesthesia, tetany and recurrent diarrhoea. Investigations revealed that she was profoundly hypocalcaemic and hypomagnesaemic $(1.76 \mathrm{mmol} /$ litre and $0.23 \mathrm{mmol} /$ litre, respectively). Serum levels of phosphate ( $1.18 \mathrm{mmol} / \mathrm{litre})$, creatinine $(60 \mu \mathrm{mol} /$ litre $)$ and bicarbonate (26 $\mathrm{mmol} /$ litre) were normal. Modest hypokalaemia $(3 \cdot 1$ $\mathrm{mmol} /$ litre) and hypoalbuminaemia ( $30 \mathrm{~g} /$ litre) were noted.

The serum immunoreactive parathyroid hormone (iPTH) level was inappropriately low at $270 \mathrm{ng} / \mathrm{litre}$ (normal range $<700$ ) and the serum 25-hydroxy vitamin D (25-OHD) level was also low at $5 \mathrm{ng} /$ litre (normal value $>8$ ). Faecal fat excretion was elevated at $33 \mathrm{mmol} / \mathrm{day}$. Urine calcium excretion was less than $1 \mathrm{mmol} /$ day.. Skeletal $\mathrm{X}$-rays showed more extensive bone destruction (Fig. 1). Echocardiography showed thickened ventricular walls with restricted movement, consistent with an infiltrative cardiomyopathy. Treatment was begun initially with $1 \alpha$ hydroxycholecalciferol $\left(1 \alpha \mathrm{OHD}_{3}\right) 2 \mu \mathrm{g}$ daily and calcium supplements, $40 \mathrm{mmol}$ daily. The serum calcium rose in 5 days to $2.16 \mathrm{mmol} /$ litre. Treatment was then given with intravenous infusions of magnesium sulphate (4 mmol/day for 4 days) which relieved her symptoms and restored serum levels of both calcium and magnesium to normal (Fig. 2). Serum iPTH levels did not change significantly. Further chemotherapy was given, but the heart 


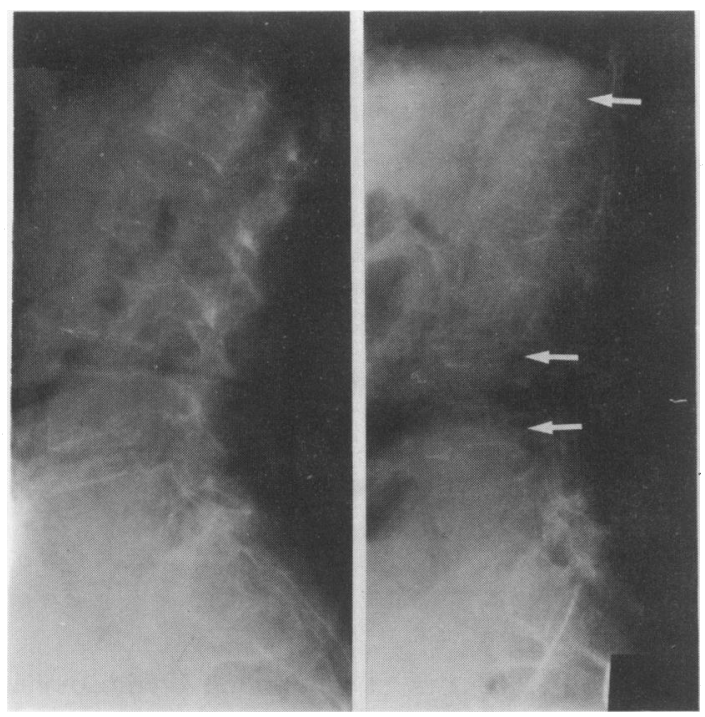

FiG. 1. X-rays of the lumbar spine taken during the first hospital admission (left) and one month before the patient's death (right). Osteopenia, diffuse skeletal disease and ballooning of the intervertebral discs are visible on the initial films.

On the follow-up pictures, which were taken only 4 months later, several vertebrae are completely collapsed (arrowed).

failure proved intractable and she died 2 months later.

At necropsy, the spleen, heart, kidneys, liver, tongue and gastro-intestinal tract all demonstrated perivascular infiltration with eosinophilic material, which stained patchily with congo-red and only the stained areas showed the characteristic green bifringence of amyloid.

On staining with peroxidase-labelled anti-light chain antiserum, extensive kappa light chain deposition was detected. The marrow findings confirmed myeloma but the parathyroid glands were not identified.

\section{Discussion}

There are 2 remarkable features of this case, firstly the occurrence of diffuse skeletal lesions in association with amyloidosis in light chain myeloma, and secondly, the occurrence of tetany despite extensive malignant bone resorption.

Although radiographically apparent osteolytic lesions occur in approximately $65 \%$ of all patients with light chain myeloma, this is an uncommon finding when there is evidence of associated amyloidosis. Bone lesions are also rare in primary amyloidosis (Khojasteh, Arnold and Farhangi, 1979) and the clinical presentation of patients with amyloid secondary to plasma cell dyscrasia is usually with amyloidrelated, rather than skeletal, symptoms (Brandt, Cathcart and Cohen, 1968; Kyle and Bayrd, 1975). In

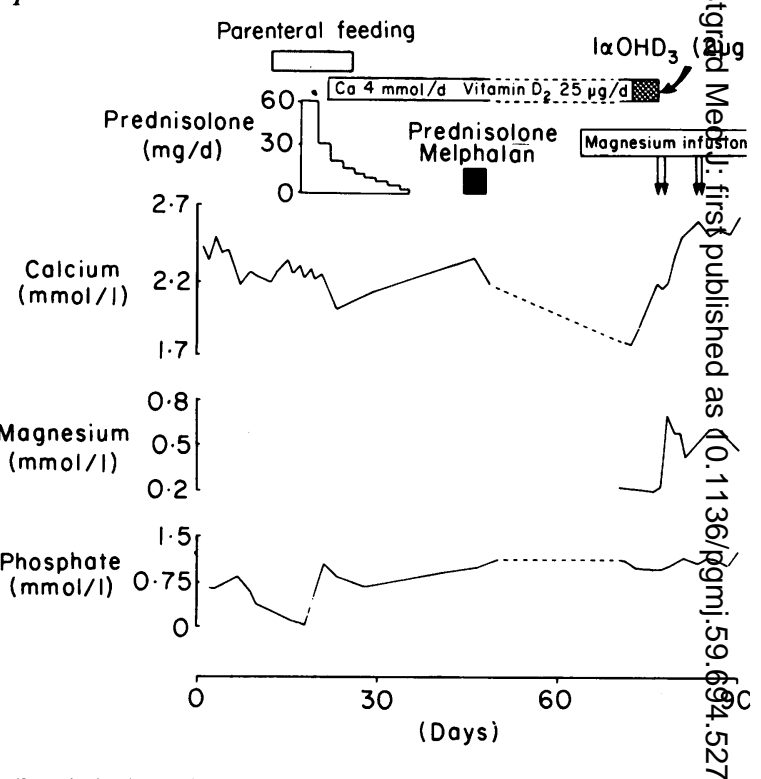

FIG. 2. Serial estimates of serum biochemistry during the 2 hospiłal admissions. The period between admissions is indicated by the broken lines. Serum calcium levels have been corrected to a standard albumin concentration of $40 \mathrm{~g}$ /litre by the addition of 0.2 $\mathrm{mmol} /$ litre for every $1 \mathrm{~g} /$ litre that plasma albumin was belowe 0 $\mathrm{g} /$ litre. The various treatments that were given are shown at the top of the figure. Note the brisk response of serum calcium to magnesium infusion. The severe hypophosphataemia that deveßpe during the first hospital admission was thought to be related introduction of parenteral nutrition and responded to an increase in the phosphate content of the feeds.

the study of Stone and Frenkel (1975), only one of patients with light chain myeloma and amyloidos had radiographically apparent skeletal disease, angl this was a solitary plasmacytoma. Our patient had diffuse osteopenia and pathological fractures of the vertebrae and ribs, suggesting advanced and aggressive osteolysis. It is not known why this commen complication of myeloma should afflict this group $\dot{s}$ infrequently. However, the survival of these patien $\$$ may be considerably shorter than that of patients with light chain myeloma without amyloidosis, so may reflect the more aggressive nature and shorteduration of the disease (Stone and Frenkel, 1975; Shustik, Bergsagel and Pruzanski, 1976).

Hypercalcaemia occurs frequently in myeloma particularly where there is radiographically ovee bone disease and renal impairment. In contrast hypocalcaemia is uncommon and tetany has, to ouP knowledge, never been reported (Drivsholm, 1964 Kyle, 1975). Many factors seem likely to hane contributed to the development of tetany. The low level of iPTH, despite severe hypocalcaemia, and the brisk response of serum calcium to magnesiu infusion, suggest that magnesium deficiency was important. Hypomagnesaemia, which is a recognized complication of malabsorption, may cause tetang 
directly, but also acts indirectly by producing hypocalcaemia through impaired parathyroid hormone release and end-organ responsiveness (Rude, Oldham and Singer, 1976). Malabsorption of vitamin D accompanied the fat malabsorption, since a 7-week course of oral vitamin $\mathrm{D}_{2}$ failed to bring serum 25OHD levels to normal. Hypovitaminosis D would thus have contributed to calcium malabsorption, hypocalcaemia and tetany. The tetany was therefore attributable to the effects of malabsorption, which was presumably due to amyloid and light chain deposition in the small bowel.

These observations suggest that the clinical spectrum of light chain myeloma with amyloid may extend to both severe osteolytic bone disease and diarrhoeal tetany.

\section{References}

Brandt, K., CathCart, E.S. \& Cohen, A.S. (1968) A clinical analysis of the course and prognosis of forty-two patients with amyloidosis. American Journal of Medicine, 44, 955.
Drivsholm, A. (1964) Myelomatosis-a clinical and biochemical study of 105 cases. Acta Medica Scandinavia, 176, 509.

Khojasteh, A., Arnold, L.K. \& Farhangi, M. (1979) Bone lesions in primary amyloidosis. American Journal of Haematology, 7, 77.

KYLE, R.A. (1975) Multiple myeloma-a review of 869 cases. Proceedings, Mayo Clinic, 50, 29.

KYLE, R.A. \& BAYRD, E.D. (1975) Amyloidosis: a review of 236 cases. Medicine (Baltimore), 54, 271.

RUdE, R.K., OldhaM, S.B. \& Singer, F.R. (1976) Functional hypoparathyroidism and parathyroid hormone end-organ resistance in human magnesium deficiency. Clinical Endocrinology, 5, 209.

Shustik, C., Bergsagel, D.E. \& Pruzanski, W. (1976) K and $\lambda$ light chain disease: survival rates and clinical manifestations. Blood, 48, 41.

STONE, M.J. \& Frenkel, E.P. (1975) The clinical spectrum of light chain myeloma: a study of 35 patients with special reference to the occurrence of amyloidosis. American Journal of Medicine, 58, 601.

(Accepted 3 December 1982) 